\title{
The Need to Adjust Lean to the Public Sector
}

\author{
Nicole Maarse and Marijn Janssen \\ Delft University of Technology, Jaffalaan 5, 2628 BX Delft, the Netherlands \\ Nicole.Maarse@leangovresearch.org, m.f.w.h.a.janssen@tudelft.nl
}

\begin{abstract}
Over the last decade all kinds of e-government processes have been developed. Governments are seeking rationalization of these processes in order to save money while maintaining or improving service levels. In the private sector Lean methods have been used to achieve these goals, whereas these are hardly explored for e-government. The goal of this paper is to translate the concept of Lean to the field of government. An in-depth case study was conducted in which Lean was applied. Lean concepts like value stream and removing of waste proved to be useful. Some public sector characteristics impede the direct use of Lean concepts. We recommend to adjust Lean to the nature of e-government. Attention should be given to public values, fragmentation, financial aspects and culture when applying the concept of Lean in the public sector and e-government.
\end{abstract}

Keywords: E-government, organizational change, organization theory, structuration theory, multidisciplinary approach.

\section{Introduction}

After having developed all kinds of processes driven by technology development, governments are seeking rationalization of their processes in order to save money while maintaining or improving service levels. Many of those processes have been developed and evolved over the years without specific attention given to the improvement. A concept that is currently embraced for improving business processes is Lean. Originally Lean was developed in and for manufacturing environments [1] and during the last decade Lean has been adopted by the services industry [2]. Lean inherently possesses viewpoints and terms that do not immediately ring bells in or are applicable to governmental environments, such as measuring of lead times/takt-time, upstream - downstream or a constant awareness of operational costs. The management concept of Lean is ill-defined [3]. Depending on perspective, Lean can both be described as a set of tools, an approach, a system, and a philosophy [4]. The absence of a clear view on Lean makes it difficult to translate the concept, but gives leeway to modify the concept to other domains, such as e-government. The challenge will be to find analogies that allow us to use the Lean methodology and tools in governments settings and ultimately identify areas and ways for improvement. The most direct transfer of Lean from manufacturing environments supposedly are voluminous production processes of tangible products in the public sector (e.g. army 
trucks). More generally, Lean is said to work best on repeatable tasks of a certain volume $[3,5,6]$, tasks found in administrative and e-government spheres.

Lean is not without criticism and the impacts remain much debated [see for example 7, 8, 9]. Lean is also associated with high levels of failure [5]. The translation of the Lean principles to practice is often complicated [10]. Lean models need to be adapted to the public sector [11]. Current literature about Lean in the public sector does not focus on translating the concept and capturing the nature of government and often remains generic [5]. Our goal is to translate the concept of Lean to e-government and understand the idiosyncratic nature of this field. We will conclude that public value fragmentation, financial aspects and culture influence the core concepts of value creation and waste.

\section{Background}

\subsection{Principles of Lean}

The concept of Lean was spread by Womack, Roos and Jones [12]. They visited and studied several Japanese businesses to find out why they did so well on the global market.. They concluded that the Toyota Production System was successful because the core processes were organized in such a way, that all activities where done in the exact right way, in de right order and at the right time, to create ultimate value for the customer. Lean production was at that time in sharp contrast with traditional mass production systems, typically characterized by batches of identical products and queues. The Lean methodology identifies five core principles or phases; Value, Value Stream, Flow, Pull and Perfection. We will use these core concept as a starting point for our research.

1. Specify value from the standpoint of the end customer, define value in terms of a specific product with specific capabilities offered at a specific time.

2 . Identify all the steps in the value stream, eliminating whenever possible those steps that do not create value.

3. Make the value-creating steps occur in tight sequence so the product will flow smoothly toward the customer. 'Flow' enables the organization to deliver more "customer value for resources". A flow is perfect when there are no stops between the order and the delivery to the customer, unless the customer might want it differently.

4. As flow is introduced, let customers pull value from the next upstream activity; design and provide what the customer wants, only when the customer wants it. 'In a pull system, the allocation of resources (humans, materials, finance) follows the customer demand' ([13], p. 16).

5. As value is specified, value streams are identified, wasted steps are removed, and flow and pull are introduced, begin the process again and continue it until a state of perfection is reached in which perfect value is created with no waste.

Taiichi Ohno, one of the creators of the Toyota Production system, stated that it was extremely important to differentiate value for the customer, from muda - the Japanese term for waste. Within the context of manufacturing systems he identified seven types 
of waste [14]. Womack and Jones [15] added an eighth. For the services sector ten forms of similar waste are identified [16]. We will use these ten waste categories to analyze our case study.

1. Overproduction - Results in an excess of products, products being made too early and increased inventory.

2. Waiting - Any idle time or period of inactivity (because an upstream activity has not delivered on time).

3. Extra processing or duplication - Any activity that does not add value to the product or service, e.g. rework, reprocessing, handling or storage that occur because of defects, overproduction or excess inventory.

4. Transport and motion - Any movement of materials, people, employees and equipment. Motion takes time and adds no value to the product or service.

5. Inventory (incorrect) - Any product or work (whether finished or not) that is not immediately used or required by the customer. Such inventory or 'storage' can result in extra processing and requires space.

6. Defects - Any product or service that is not according to the needs or specifications of the customer, resulting in rectification or rework and/or customer dissatisfaction.

7. Underutilization of people - Also referred to as 'a waste of talent', this happens when people are not 'used' to their full talent, skills or knowledge..

8. Lack of customer focus - Poor attention to the customer resulting in dissatisfaction because of defects or treatment.

9. Unclear communication - Use of incorrect information or an unclear workflow, which can result in defects.

10. Variation - Lack of procedures or standard formats

Hines et al. [3] discuss the four main criticisms of Lean; the lack of contingency and ability to cope with variability, the lack of consideration of human aspects (see also [17]), the narrow operational focus on the shop-floor and not considering the strategic level. They conclude that Lean has evolved and different applications and contingencies have been explored, while maintaining the Lean principles developed by Womack and Jones [15]. On that account the mentioned criticisms are less relevant these days. They state that a contemporary version of Lean consists of two levels; operational and strategic, whereby the operational level is about eliminating waste and the strategic level is about understanding value. Their comparison of Lean thinking to the stages of organizational learning emphasizes 1) that Lean has evolved and 2) that Lean is more than a tool but rather a mindset for which a level of 'organizational internalization' is required. "As such, this development is one of testing the boundaries of Lean thinking and the contingent modifications of the approach (within sectors, across businesses etc.) rather than any fundamental change to the Lean enterprise "design logic" (p.1005). We adopt this thinking in this paper and when translating the concept of lean to e-government. 


\subsection{Application of Lean and the Public Sector}

For the services industry it has been concluded that Lean has the potential to contribute to aspects such as efficient production processes, increased product variety and customer focus/satisfaction. But that attention should be paid to the reinterpretation of Lean tools and concepts such as value [16, 18, 19]. In e-government many public organizations deliver services to accomplish social values and to serve administrative goals and their processes inherently reflect this. Since Lean has been used in the services sector, we might assume the application of Lean in the public sector could be a legitimate and worthwhile one but might require adaptions.

Over recent years public organizations have applied Lean, although only for a limited type of processes. Often Lean projects were implemented in only a sub-part of public organizations [20]. Apart from health care and maintenance of army trucks, little application and research with regard to Lean in the public sector has taken place, although some organizations have adopted a so called 'Lean services approach' [6]. Some of these adoptions have explicitly gone under the New Public Management heading, which over the last two decades has strived to bring more control, efficiency and performance than the traditional Weberian view, by implementing more marketoriented elements into the public sector. Recently however, research in public management is debating how to address the supposed weaknesses of NPM. Two examples of research in typical public sector organizations identify critical success factors and potential barriers for successful adoption and implementation of Lean thinking in public sector environment $[5,6,21]$. These include: organizational culture and ownership, organizational readiness and employee support, objective (cost cutting/lay-offs or improvement of process), management commitment and capability, need for change, link between improvement programs and strategy, adequate amount and skills of resources, training and knowledge transfer, communication, clear customer focus, people working and thinking in silos or whole systems thinking, too many procedures and targets, awareness of strategic direction, general belief that staff are overworked and underpaid, rewards, 'identifiability' of impact and realistic time plan/natural pace of change. Womack and Jones [15] describe Lean as a philosophy which should be adopted throughout the whole organization. Radnor and Walley [21] emphasize that Lean works best when both senior management and employees are trained and involved.

The public sector has characteristics that may impose barriers for the application of Lean. Bharosa et al. [22] identify a list of relevant differences between the public and the private sector including equal access and rights, lack of choice and no competitors, legislations, transparency and accountability, fragmented decision-making and public values. Rainey et al. [23] present an extensive and detailed list of differences between the public and private sector, such as degree of market exposure, political influences, breadth of impact, public scrutiny, complex objectives and decisions criteria and personal characteristics of employees. Challenges for Lean application in the public sector described by Bhatia et al. [24] include 'taking the customer's perspective' and Rainey et al. [23] list 'less focus on customer as a characteristic stemming from/ finding its cause in less market exposure in the public sector'. 


\section{Research Approach}

By striving to understand the nature and specific nature of Lean within government, we opted for a qualitative approach based on a case study research [25]. Case study research is a common qualitative method used in the information systems (IS) field [26]. The case study research methodology is particularly well-suited to IS research, since the object of the discipline is the study of IS in organizations, and the interest is shifted to organizational rather than technical issues' [27]. This research was based on interviews, document collection and evaluation in a qualitative setting. Ten interviews and several workshops were organized with over 20 administrative staff and public managers. One of the authors was involved in the process improvement and conducted process modeling and analysis tasks and presented these in workshops to gain feedback. Both feedback concerning the process improvements as well as the method was collected. Documents relating to the initiation of Lean projects, decisionmaking, implementation, use and improvement were investigated in the first half of 2012.

A case study was conducted within a large Dutch governmental service agency, that was considered a frontrunner in the application of Lean. Its processes have different levels of complexity and often include many instances of interaction with citizens. Armistead et al. [28] identify five types of processes within organizations; operational, support, direction-setting, managerial and change processes. Much of the existing research on Lean concentrates on operational processes. Our case study concerns a support process within a large public organization with typical complexities of the public sector, as the procurement is constrained by legislation, heterogeneous stakeholders are involved and the activities are fragmented over several departments. In this we confront the Lean approach with the public sector characteristics.

\section{Case: Lean in Practice}

\subsection{Tender Process}

In order to translate the concepts of Lean to the public sector a case of the "tender process' in a large Dutch government administrative agency was investigated. This case study was conducted during the first half of 2011. This administrative body has nearly 20.000 employees of many different blood types, due to mergers in the last 7 years. One of the more extensive and complex Lean projects concerned the 'tender process'. The deputy director responsible for purchasing was keen on reducing the lead times of tenders, as public procurement laws stipulate strict terms for contracting authorities for contracts above a certain financial threshold. Not complying with these can lead to legal actions and financial and reputational damages. The time squeeze would allow suppliers to be in the driver's seat. Also actors within the process would complain that the process itself was difficult because 'everyone wanted to say something about it'. 
The tender process consists of three phases; Specification, Selection and Contracting. The average lead time of a tender turned out to be 452 days, whereas the process was designed under the assumption that it would take a maximum of 365 days; the trigger of the process is a sign (from system or responsible purchase manager) that a contract will expire within a year, or an internal client/department requesting the purchase of a certain product or service. So the organization would have a year to conclude a new contract. The specification phase took about half of the 452 days. For scoping purposes, the three phases were further researched separately. The specification phase consists of five main process steps (Fig. 1). The result of this phase is a Request for Proposal (RfP), which is published and serves as an invitation for potential suppliers to be a candidate in the tender and send in their proposals. The RfP contains the selection criteria used in the selection phase to select a contractor.

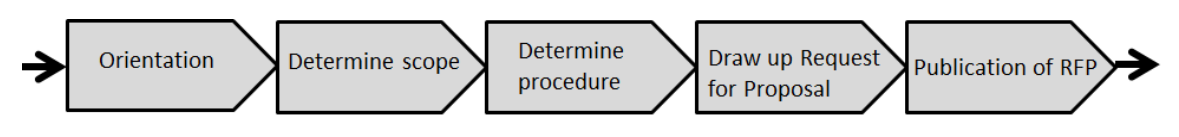

Fig. 1. Tender process: specification phase

\subsection{The Five Principles of Lean in Case Study}

Value: the customer in our case was the department in need of a certain product or service. This internal customer valued a signed contract, delivery of the product on time, and a product that was according to their needs. Of value in the specification phase is an RfP containing complete, correct and specific formulation of the needs and selection criteria, on which a selection can adequately be based.

Value Stream: For this project, we engaged a group of employees that were part of this process and fulfilled various roles. Together we mapped all 35 tasks within this process. This exercise gave us an insight into the order of activities, the time they took, who executed them and what kind of problems the employees encountered during execution. This process overview allowed us to identify the waste in the process. Table 1 shows that all of the waste categories were identified. In general, we concluded that about half of the steps did not add to the value of the desired output, e.g. waiting time, procedural/formal steps, steps not used to their purpose or another tool could provide more value.

Flow; First of all, many moments of transfer impede flow, because people of many different departments were involved usually one after the other. Secondly, the ideal tender process was not clear, nor was it in control in terms of steering progress and quality. In general cooperation between departments was difficult, due to internal focus (vs. seeing the whole) and focus on the content of laws and policies (vs. process view).

Pull; The customer did not act as a customer in defining exactly what was wanted or valued (not in terms of product that was the subject of the tender, nor in terms of what he needed the purchase department to do to help him get it). The process was not designed to have a trigger from 'the end of the line'/ downstream. 
Table 1. Waste identified in tender process

\begin{tabular}{|c|c|c|}
\hline 1. & Overproduction & $\begin{array}{l}\text { Activities executed before the content has been agreed upon by other } \\
\text { actors (adjustments), documents that are not read (format not } \\
\text { suitable, formalities) }\end{array}$ \\
\hline 2. & Waiting & $\begin{array}{l}\text { Documents waiting to be accorded, waiting for meetings to be } \\
\text { planned, full agendas, no priority, many actors, conflicting and } \\
\text { inexplicit interests }\end{array}$ \\
\hline 3. & Transport/Motion & Collecting signatures \\
\hline & $\begin{array}{l}\text { Extra processing } \\
\text { and duplication }\end{array}$ & $\begin{array}{l}\text { Adjustments to documents, rewriting in other format, signatures } \\
\text { needed for (formal) approval, unnecessary reporting (formalities) }\end{array}$ \\
\hline & $\begin{array}{l}\text { (incorrect) } \\
\text { Inventory }\end{array}$ & Looking for the right document, unnecessary paper copies made \\
\hline & Defects & $\begin{array}{l}\text { Unclear or lacking selection criteria (which would cause delays } \\
\text { during the selection phase), top management adjustment in end of } \\
\text { process, incomplete documents, late input }\end{array}$ \\
\hline 7. & $\begin{array}{l}\text { Under-utilization } \\
\text { of people/talent }\end{array}$ & $\begin{array}{l}\text { Purchase manager printing documents or collecting signatures, } \\
\text { inadequate forms or system, limited authority/ dependence on formal } \\
\text { functions }\end{array}$ \\
\hline & $\begin{array}{l}\text { Lack of customer } \\
\text { focus }\end{array}$ & $\begin{array}{l}\text { Poor understanding of customer, skills /knowledge for clear } \\
\text { specification }\end{array}$ \\
\hline 9. & $\begin{array}{l}\text { Unclear } \\
\text { communication }\end{array}$ & $\begin{array}{l}\text { Incorrect or incomplete information, lack of standard formats/ } \\
\text { common language and ground, unclear work flow (mainly across the } \\
\text { departments), inadequate cooperation, no clarity on responsibilities } \\
\text { and mandates }\end{array}$ \\
\hline 10. & Variation & $\begin{array}{l}\text { Lack of procedures or standard formats, standard time not defined, } \\
\text { procedures and standard formats exist but not used or not adequate } \\
\text { for the purpose they needed to serve. }\end{array}$ \\
\hline
\end{tabular}

Perfection; Previous steps were not fulfilled. During the improve and control (implementation) phases aspects of culture and change proved to be crucial (skepticism of change or drive for improvement, ownership/responsibility). Management commitment was lacking in the sense that managers were not keen on being transparent about the fact that their process could be done quicker and on a smaller budget (that would reduce their budget and power) and or an employee would be assigned to the Lean project, but in practice would not be given the time.

The measures implemented to reduce the lead times to less than a year and implement a controlled process with a higher quality outcome included the set up of multidisciplinary teams, designing a process in such a way that waiting times were significantly reduced and more activities executed simultaneously, more understanding of the tender process, redesign of formats, use of system throughout organization, paying special attention the quality of the product by for instance implementing quality checks/ go-no go decisions and training both purchasing and internal customers to be more specific on formulating needs and specs. Even though the implementation of these measures took time (and the lead times of tender did not allow a quick evaluation), the first results showed shorter lead times, more flow and a boost of employee and management sense of improvement, process view and morale. 


\section{Discussion; Translation Lean to E-Government}

In the case the five Lean principles were used as a diagnostic tool. Assessment using the five principles of Lean showed that this process was 'far from Lean'. Hence, Lean can contribute to the identification of areas for improvement. The definition of value, visualization of the value stream and the identification of waste (the first two principles of Lean) was a valuable exercise, though purely diagnostic. Assessing the other three principles of Lean (flow, pull and perfection), resulted in the conclusion that there was no flow, no pull and no perfection. When attempting to translate the Lean concept to this new domain, we also need to consider (next to its use for assessment or diagnostic purposes) its potential to actually eliminate waste and how Lean could be fully implemented (i.e. all five principles fulfilled); or how both Hines' operational and the strategic level are translated [3]. We are inclined to identify a 'diagnostic' and 'holistic' purpose or level at which Lean can be considered.

Our findings suggests that a number of (interdependent) factors stand in the way of successful elimination of waste and establishment of flow, pull and perfection. Some of which are characteristic for e-government or fundamental to government structure, some are related to culture, public values and democratic system. Challenges and tensions include the following:

- System of appropriations and top management commitment; we see that adverse aspects play a role (e.g. a manager may be keen on improving his/her process but not on being transparent about the fact that this process can be done on a smaller budget, because that would mean a smaller budget would be appropriated in the following year. Such a change is also perceived as a loss of power or importance;

- Lack of cost-efficient and cost-effective awareness and behavior; sense of urgency or commitment to quality, few triggers to formulate needs and specs adequately, no clear customer focus or recognition of customer. The fact that nor customer nor supplier in the tender process acted as such may be more typical for support processes as the customer is internal. Nevertheless improvements are possible by taking the customer into account, including a better specification of the needs and selection criteria;

- Conflict between customer wishes (fast and low cost) with public values (transparent, correct and accountable);

- Waste from one view might not be waste from another view. Efficiency is favored over sound and transparent decision-making processes as is common in the public sector. The solely focus on waste and value from a customer perspective neglects the requirements coming from the broader social and democratic context;

- Emphasis on content of laws and policies and formalities, resulting in inward focus and lack of process view. Law is dominating the process and not the objective for having these laws;

- Bear-garden of decision-making; lack of effective control or means to effectuate decisions, activities fragmented over many departments, no culture where performance and renumeration/position management are linked; 
Culture is crucial to successful improvement with Lean. It encompasses a wide range of factors seen in our case study, such as ownership, sense of whole and process, breadth of focus, commitment to quality or confidence in improvement and attitude towards change. It is also a factor that is manifest and specific for the public sector, likely to present the biggest impediment for successful implementation of Lean if not enough attention is paid to communication, motivation, empowerment, involvement and drivers.

Policies and legislation themselves do not necessarily have to constrain the possibilities of identifying and reducing waste; public procurement law was a main driver of the adoption of Lean and not an impediment, Lean helped to identify opportunities for improvement and contributed to the reduction of lead times of this support process, without compromising any regulations. However in the case it was not assessed whether the stipulations of public procurement law themselves where Lean, rather we took them as a given. We mostly identified formalities as 'not lean' since they did not contribute to the value materially. However, such legal constraints do have a value at a higher level of abstraction (in maintaining legality and legitimacy) and should therefore not always be counted as waste, or on the contrary are core to the role of government. Characteristics of government and its structures find their base in phenomena such as democracy, rule of law and separation of powers, which are generally valued greatly, or embed greatly valued aspects of life. Many structures (such as bureaucracies) and procedures have been built upon these phenomena and are firmly embedded in today's public sector. Even though, these are always subject of public debate, especially when fuelled by financial crises and public/societal discontent with governments. In our case, the supplier and customer were easily identified (despite the fact that they did not act as stereotype suppliers and customers) and so was the identification of 'value', which is the first principle of Lean. In general however (and potentially in further research into other kinds of government processes), it could prove to be difficult to identify who is the customer and what is of value to the customer. For collective goods in general there is no direct link between the demand and supply, nor signs for customers or citizens to 'value' a product or service. Instead, there is more push than pull and the supplier of services (the government) decides what is offered and when. This assertion brings us to the phenomenon of 'public value'; the customer of government in general is not only the citizen, but also a society as a whole. Lean puts the customer in front and do not consider other factors coming from the democratic system. In the quest to find the limits of Lean thinking and stretching its principles in order to find ways to improve public sector performance, what is of value and to whom needs to be determined, which is a much more complex exercise. Since NPM has failed to bring about a panacea for managing the public sector, the paradigm of Public Value Management has become increasing popular. The value then, comes in the form of enhanced safety, less poverty or better services and is determined by citizens. In this perspective citizens are the shareholders in how their tax is spent [29]. The focus is not primarily on efficiency, but also on creating social values like safety and accountability. Barking up the tree of public value for a useful interpretation of 'value', as the public sector equivalent to customer value in the private sector, needs further research. 
Not all characteristics of the public sector need necessarily form impediments for successful implementation of Lean, rather different characteristics ask for different (management, change and process design) solutions. Some might even prove to be, if used appropriately, opportunities. For instance the fact that a sense of importance is present in culture ('we fulfill an important societal role') might be used to the advantage of improvement, when people are motivated by the fact that they contribute to the creation of public value.

\section{Conclusions and Further Research}

The concept of Lean was investigated in the setting of e-government in order to find out how and whether the application of Lean would be a valuable exercise. Whereas Lean is mainly used for operational processes, we conclude that Lean can also identify areas and solutions for improvement, especially waste, in a support process within a large public organization. It can contribute to the reduction of waste or the 'design-in' of flow and pull. In that sense Lean is a valuable diagnostic tool. But several tensions were found. The primarily focus on efficiency and customer does not take public values into account. Also the focus on customer (citizen) value creation does not consider the value for the democratic system. When adopted at a strategic level and implemented fully, it can optimize processes, stimulate culture and lead to continuous improvement. However, characteristics of government permeate all sorts of government process and greatly impede both the adoption, implementation and application of Lean in e-government settings. These specifics require adjustment of Lean tools and interpretations for better fit of application and solutions. In particular the following concepts should be given attention.

- Waste categories; some are less applicable or recognizable (transport), others may come in a particular form, such as the added 'incorrect' to inventory for use in service settings. Some aspects are not waste and necessary for the proper working of the democratic system

- Value; Government is about creating public value. Therefore the concept of Lean with its focus on customer (citizens) value should be complemented with public values. Opportunities for Lean in the public sector may lie in the concept of creating public value; where traditional Lean thinking is about creating customer value, Lean thinking for the public sector could be more holistic, by focusing on creating public value.

- Customer; in public settings customers in the actual sense of the word hardly exist. So they are harder to identify. In the Lean philosophy they are crucial, as they are the starting point for all other principles. We suggest that taking public value as a base can be useful.

Since aspect of culture such as both employee and management commitment are crucial, much attention must be paid to the establishment of a culture that recognizes the potential of Lean, improvement and joint creating of value. Further research 
should answer how management and employee commitment in government settings specifically can be realized.

For the translation of the concept of Lean, we suggest that it could be valuable to make a clear distinction between 1) factors that determine the applicability of Lean in new settings (the applicability itself is enhanced by the evolution, broader interpretation or translation of Lean), 2) the factors that are relevant for the adoption and acceptance of Lean as a methodology and 3) impediments for successful implementation and improvement (of which 2. is a part). Such a distinction may help to ultimately separate the 'controllable variables' from 'unchangeable factors' and identify successful ways to improve government processes. In our case it was not assessed whether the stipulations of public procurement law themselves where Lean. The leanness of legislation and policy should be further researched.

\section{References}

1. Womack, J.P., Roos, D., Jones, D.: The Machine That Changed the World. Rawson and Associates, New York (1990)

2. George, M.L.: Lean Six Sigma for Service: How to Use Lean Speed and Six Sigma Quality to Improve Services and Transactions. McGraw-Hill (2003)

3. Hines, P., Holweg, M., Rich, N.: Learning to evolve A review of contemporary lean thinking. International Journal of Operations \& Production Management 24, 994-1011 (2004)

4. Graban, M.: Lean Hospitals - Improving Quality. Patient Safety and Employee Satisfaction, New York (2009)

5. Pedersen, E.R.G., Huniche, M.: Determinants of lean success and failure in the Danish public sector A negotiated order perspective. International Journal of Public Sector Management 24, 403-420 (2011)

6. Radnor, Z., Walley, P., Stephens, A., Bucci, G.: Evaluation of the Lean Approach to Business Management and Its Use in the Public Sector (2006)

7. Radnor, Z., Boaden, R.: Lean in the public services: panacea or paradox? Public Money and Management 28, 3-7 (2008)

8. Mehri, D.: The darker side of lean: an insider's perspective on the realities of the Toyota production system. Academy of Management Perspectives 20, 21-42 (2006)

9. Hines, P., Rich, N.: The Seven Value Stream Mapping Tools. International Journal of Operations and Production Managemen 17, 46-64 (1997)

10. Wu, Y.C.: Lean Manufacturing: A Perspective of Lean Suppliers. International Journal of Operations \& Production Management 23, 1349-1376 (2003)

11. Erridge, A., Murray, J.G.: The application of lean supply in local government: the Belfast experiments. European Journal of Purchasing \& Supply Management 4, 207-221 (1998)

12. Womack, J.P., Roos, D., Jones, D.: The Machine That Changed the World Rawson and Associates, New York (1990)

13. Jones, D.T., Mitchell, A.: Lean thinking for the NHS. NHS Confederation (2006)

14. Ohno, T.: Toyota production system: beyond large-scale production. Productivity Press, New York (1988)

15. Womack, J.P., Jones, D.T.: Lean Thinking: Banish waste and create wealth in your organization. Simon \& Schuster, New York (1996) 
16. Bonaccorsi, A., Carmignani, G., Zammori, F.: Service Value Stream Management (SVSM): Developing Lean Thinking in the Service Industry. Journal of Service Science and Management, 428-439 (2011)

17. Carter, B., Danford, A., Howcroft, D., Richardson, H., Smith, A., Taylor, P.: Lean and mean in the civil service: the case of processing in HMRC. Public Money \& Management (2011)

18. Bowen, D.E., Youngdahl, W.E.: 'Lean' Service: In defense of a production line approach. International Journal of Service Industry Management 9, 207-225 (1998)

19. Piercy, N., Rich, N.: Lean transformation in the pure service environment: the case of the call service centre. International Journal of Operations \& Production Management 29, 54 76 (2009)

20. Pedersen, E.R.G., Huniche, M.: Negotiating Lean; The fluidity and solidity of new management technologies in the Danish public sector. International Journal of Productivity and Performance Management 60, 550-566 (2011)

21. Radnor, Z., Walley, P.: Learning to Walk Before We Try to Run: Adapting Lean for the Public Sector. Public Money \& Management 28, 13-20 (2008)

22. Bharosa, N., Feenstra, R., Gortmaker, J., Klievink, B., Janssen, M.: Rethinking Serviceoriented Government: is it really about services? In: Bouwman, H., Bons, R., Hoogeweegen, M., Janssen, M., Pronk, H. (eds.) Let A Thousand Flowers Bloom. Essays in Commemoration of Prof.dr. René Wagenaar. IOS Press, Delft (2008)

23. Rainey, H.G., Backoff, R.W., Levine, C.H.: Comparing Public and Private Organizations. Public Administration Review 36, 233-244 (1976)

24. Bhatia, N., Drew, J.: Applying Lean production to the public sector. The McKinsey Quarterly (2006)

25. Yin, R.K.: Case Study Research: Design and methods. Sage publications, Newbury Park (1989)

26. Orlikowski, W.J., Baroudi, J.J.: Studying Information Technology in Organizations: Research Approaches and Assumptions. Information Systems Research 2, 1-28 (1991)

27. Benbasat, I., Goldstein, D.K., Mead, M.: The Case Research Strategy in Studies of Information Systems. MIS Quarterly 11, 369-386 (1987)

28. Armistead, C., Pritchard, J.-P., Machin, S.: Strategic business process management for organizational effectiveness. Long Range Planning 32, 96-106 (1999)

29. Horner, L., Hazel, L.: Adding public value. The Work Foundation (2005) 